\title{
Vitamin D receptor gene polymorphisms are associated with triceps skin fold thickness and body fat percentage but not with body mass index or waist circumference in Han Chinese
}

Fang Shen ${ }^{1}$, Yan Wang ${ }^{1}$, Hualei Sun ${ }^{1}$, Dongdong Zhang ${ }^{1}$, Fei Yư ${ }^{1}$, Songcheng Yu ${ }^{1}$, Han Han ${ }^{1}$, Jun Wang ${ }^{1}$, Yue Ba ${ }^{2}$, Chongjian Wang ${ }^{3}$, Wenjie Li $i^{1}$ and Xing Li ${ }^{*}$

\begin{abstract}
Background: Evidence shows that low serum vitamin D concentrations account for an increased risk of obesity by inducing vitamin D receptor (VDR) hypofunction. Although the correlation between single nucleotide polymorphisms (SNPS) of VDR gene and obesity-related anthropometric measures (such as body mass index [BMI] and waist circumference[WC]) has already been tested, there are only few studies on the association between direct measures of body fat percentage (BFP) and triceps skinfold thickness and the SNPs of VDR. The aim of the present study was to evaluate the effect of VDR gene polymorphism on multiple obesity indexes in Han Chinese, including BMI, WC, BFP and triceps skinfold thickness.
\end{abstract}

Methods: In this cross-sectional study, five hundred and seventeen healthy Chinese adults were enrolled in the trial. Four loci in VDR gene (rs2228570 [Fokl], rs2189480, rs2239179 and rs7975232[Apal]) were genotyped by TaqMan probe assays. Obesity indexes including BMI, WC, BFP and triceps skinfold thickness were used to evaluate the relationship to the VDR SNPs. Multiple logistic regression, linear regression and general multifactor dimensionality reduction (GMDR) were performed to analyze the correlation of VDR gene and obesity indexes.

Results: None of the VDR SNPs were associated with BMI and WC, the $C$ allele of Fokl and the T allele of Apal were associated with an increase in BFP $(\beta=0.069, P=0.007 ; \beta=0.087, P=0.022$ respectively); the $G$ allele of rs 2239179 and the $T$ allele of Apal were associated with an increase in triceps skin fold thickness $(\beta=0.074, P=0.001 ; \beta=0$. $122, P<0.001$ respectively). In regards to adiposity-related metabolic parameters, we found that the GT genotype of Apal was associated with higher level of total cholesterol (TC) $(P=0.013)$ and Low-density lipoprotein cholesterol (LDL-C) $(P=0.001)$.

Conclusions: Though we failed to prove that VDR SNPs were in correlation with BMI and WC, we did establish the association between VDR variants and BFP, as well as triceps skinfold thickness. Data obtained suggested that the $V D R$ variants play an important role in regulating adipose tissue activity and adiposity among Han Chinese.

Keywords: VDR polymorphisms, Triceps skinfold thickness, Body fat percentage, Interaction, Adiposity

\footnotetext{
* Correspondence: 15093285830@163.com

'Department of Nutrition and Food Hygiene, College of Public Health,

Zhengzhou University, 100 Kexue Avenue, Henan 450001, China

Full list of author information is available at the end of the article
}

(c) The Author(s). 2019 Open Access This article is distributed under the terms of the Creative Commons Attribution 4.0 International License (http://creativecommons.org/licenses/by/4.0/), which permits unrestricted use, distribution, and reproduction in any medium, provided you give appropriate credit to the original author(s) and the source, provide a link to the Creative Commons license, and indicate if changes were made. The Creative Commons Public Domain Dedication waiver (http://creativecommons.org/publicdomain/zero/1.0/) applies to the data made available in this article, unless otherwise stated. 


\section{Introduction}

Worldwide obesity has nearly tripled since 1975. In 2016, more than 1.9 billion adults (aged 18 and older) were overweight, among which more than 30\% were obese, triggering a pandemic [1]. Due to rapid changes in social politics, economy, culture, (For instance, experiencing a "nutrition transition") obesity has become a serious issue for China in the past decades [2]. The accumulation of excess body fat contributes to higher morbidity and mortality rates of non-communicable diseases (NCDs), such as cardiovascular disease, chronic obstructive pulmonary disease, lung cancer, and diabetes $[3,4]$. In order to assess the magnitude of the problem, the relevance between adiposity and NCDs are described using various anthropometric indicators such as body mass index (BMI), waist circumference (WC) and skinfold thickness. Previous studies have shown that high subcutaneous fat increases the risk of cardio-metabolic diseases independently $[5,6]$. Meanwhile, individuals with a healthy body composition prefer to gain a healthier cardio-metabolic profile later on in life, and similar situations could be found in adult population with diabetes mellitus, hypertension, metabolic syndrome, and several of cancer [7-9].

Both vitamin D deficiency and insufficiency are common in China $[10,11]$. Since negative correlation between serum $25(\mathrm{OH}) \mathrm{D}_{3}$ level and high adiposity has been well established [12-14], recent studies have focused on the physiological functions of vitamin D in adipose tissue [15-17]. It is well known that adipose tissue plays a pivotal role in energy balance and glucose homeostasis and serves as the main storage site for vitamin D [18]. Even human SAT (Subcutaneous adipose tissue) and VAT (Visceral adipose tissue) express VDR and enzymes involved in vitamin D metabolism [19]. Vitamin D is active in adipose tissues and act as a key regulator of gene expression, as well as signal transductions [20]. It is worth noting that vitamin D couples with its receptor $(V D R)$ to exerts multiple biological functions and the binding of vitamin $\mathrm{D}$ to $V D R$ plays an important role in regulating adipogenesis both in vivo and invitro $[21,22]$.

A body of studies have been conducted to investigate the association between VDR variants and different adiposity phenotypes [23-27], so far failed to reach a consensus. Furthermore, most of these studies were involved in anthropometric measurements (BMI and WC), but not obesity biomarkers of regional fat accumulation such as subcutaneous fat (skinfold thickness) or total fat accumulation such as body fat percentage[BFP]. As BMI and WC cannot distinguish fat from lean mass, explicit understanding of these two obesity biomarkers may provide important insights into the association between $V D R$ variants and BMI or WC in different studies.
To our knowledge, the relationship between $V D R$ variants and adiposity in Han Chinese are rarely investigated, let alone the regional and total body composition. Therefore, the possible relationships between single-nucleotide polymorphisms (SNPs) in $V D R$ and multiple adiposity traits like BMI, WC, BFP and skin fold thickness are discussed in the study, Aiming to illustrate the biological significance of $V D R$ polymorphisms on adiposity and may contribute to the identification of novel therapeutic strategies to prevent or treat adiposity and adiposity-related disorders among Han Chinese.

\section{Materials and methods \\ Study population}

Between June and July of 2013, a total of 1851 subjects were selected in the present cross-sectional study, which was conducted in Henan Province, a central area of China. Participants' age ranged between 18 and 90 years. Exclusion criteria was chronic non-communicable diseases, acute diseases, taking vitamin $\mathrm{D}$ or calcium supplementation, and cholesterol-lowering medications. Finally, 517 (259 women and 258 men) subjects were eligible for analysis. The study was conducted in accordance with the guidelines set out in the Declaration of Helsinki and was approved by the Zhengzhou University Medical Ethics Committee. All the participants were given written informed consent before any collection of samples and data.

\section{Data collection}

At enrollment, all participants received clinical examination and anthropometric measurements undertaken by trained observers. Additionally, a standard questionnaire was used to obtain sociodemographic data regarding age, dietary intake, physical activity, family history of obesity, and medication use. Height, WC and hip circumference were measured to the nearest $0.1 \mathrm{~cm}$ by using a metric scale; WC was measured at the midpoint between the last rib and the iliac crest. Triceps skinfold thickness was measured from the left side of the body to the nearest $0.1 \mathrm{~mm}$, using a Holtain skinfold caliper (Holtain Ltd., Crymych, UK), at the flowing sites: halfway between the acromion process and the olecranon process. Weight and BFP were assessed by bioelectrical impedance analysis using the InBody 230 bioimpedance analyzer (Biospace CO Ltd., 518-10 Dogok2-dong, Gangnam-gu, Seoul, Korea). Weight was measured to the nearest $0.1 \mathrm{~kg}$ when the subjects were in their underwear and were not wearing shoes. BMI, waist-hip-ratio (WHR), waist-height-ratio (WHtR) were calculated as follows:

$$
\mathrm{BMI}=\text { weight }(\mathrm{kg}) /\left(\text { height }^{*} \text { height }(\mathrm{m})\right)
$$




$$
\begin{aligned}
\mathrm{WHR} & =(\mathrm{WC}(\mathrm{cm})) /(\operatorname{Hip}(\mathrm{cm})) \\
\mathrm{WHtR} & =(\mathrm{WC}(\mathrm{cm})) /(\operatorname{height}(\mathrm{cm}))
\end{aligned}
$$

On the basis of Chinese BMI categories, subjects were divided into four groups: underweight $\left(<18.50 \mathrm{~kg} / \mathrm{m}^{2}\right)$, normal weight $\left(18.50-23.99 \mathrm{~kg} / \mathrm{m}^{2}\right)$, overweight $(24.00-$ $\left.27.99 \mathrm{~kg} / \mathrm{m}^{2}\right)$, and obesity $\left(\geq 28.00 \mathrm{~kg} / \mathrm{m}^{2}\right)$ [28]. Abdominal obesity was defined as $\geq 90 \mathrm{~cm}$ for men and $\geq 80 \mathrm{~cm}$ for women [29].

Furthermore, after an overnight fast of at least $8 \mathrm{~h}$, blood tests were used to determine the lipid profile (triglyceride [TG], total cholesterol [TC], high-density lipoprotein cholesterol [HDL-C]) by using an automatic biochemical analyzer (Shanghai Kehua Bio-engineering Co, Ltd. (KHB), Shanghai, China). Low-density lipoprotein cholesterol (LDL-C) was calculated based on the Friedewald equation.

\section{Selection and genotyping of SNPs}

SNPs were screened from SNP haplotype map, NCBI database and a numerous review of literature. In addition, the selection of particular SNPs was based on the minor allele frequency (MAF) $>0.05$, possible functional consequences and previous association with vitamin D level or indices of obesity or adiposity. Finally, we selected four SNPs, namely rs2228570 (FokI), rs2189480, rs2239179, rs7975232 (ApaI). Genomic DNA from peripheral blood was isolated by the standard procedures (DNA blood kit; Bioteke, Beijing, China). Genotyping involved use of an Applied Biosystems (7500 FAST Real-Time PCR system; Applied Biosystems, Foster City, USA).

\section{Statistical analysis}

Continuous variables (normal distributed) were represented as mean \pm standard deviation and were analyzed by student's t-test, while quantitative data because of skewed distribution were illustrated as medians with corresponding quartile range and were analyzed by Mann-Whitney U-test. The Chi-squared test was used for categorical data. Departure from the Hardy-Weinberg equilibrium (HWE) was assessed in controls by using online software (http://shesisplus.biox.cn/SHEsis.html\#).

Logistic regression for multivariate analyses was used to examine association between $V D R$ variants and risk of overweight/obesity and abdominal obesity with adjustment for age, gender, family history of obesity, alcohol use, high-fat diet, vegetables consumption, and physical activity, assuming additive and dominant models of inheritance. Linear regression analysis was then used to examine the genetic association with the continuous outcomes (BFP, triceps skinfold thickness) with adjustment for age, gender, alcohol, high-fat diet, vegetable consumption, physical activity and the family history of obesity. One of the four possible models (additive, codominant, dominant and recessive) in the linear model, we selected the additive model because it generally reflects the additive contribution to risk for complex diseases. The relationship between the VDR polymorphism and adiposity-related metabolic parameters was analyzed by Analyses of Variance (ANOVA). Statistical values were performed with SPSS version 21.0 (IBM Corp., Chicago, IL, USA).

Generalized multifactor dimensionality reduction (GMDR) method permits adjustment for discrete and quantitative covariates and is applicable to both dichotomous and continuous phenotypes in various population-based study designs [30]. Analysis of the interaction on continuous phenotype (BFP and triceps skinfold thickness) between gene and gene, gene and environment was performed by GMDR (GMDR, version 0.7, University of Virginia, USA). The model with highest cross-validation consistency (CVC) and the maximum testing balanced accuracy was considered as a best model. Statistical tests were two-sided and $P$-values of $<0.05$ were considered significantly.

\section{Results}

\section{Basic characteristics}

Clinical features and anthropometric measurements of the study subjects are shown in Table 1. Overweight and obesity group had higher levels of BMI, WC, WHR, WHtR, triceps skin fold thickness, BFP, LDL-C, TC, and TG than the normal weight group. Conversely, HDL-C was significantly lower in overweight and obesity group than normal weight group.

Data are given as the mean $\pm \mathrm{SD}$, as $\mathrm{n}(\%)$ or median (quartile range). BMI, body mass index; WC, waist circumference; WHR, waist-hip-ratio; WHtR, waist-height-ratio; HDL-C, high-density lipoprotein cholesterol; LDL-C, low-density lipoprotein cholesterol; TC, total cholesterol; TG, triglyceride.

\section{Association analysis of overweight/obesity and abdominal obesity and the distribution of the VDR SNPs}

The allele and genotype distribution of FokI, rs2189480, rs2239179, and ApaI are given in Additional file 1: Table $\mathrm{S} 1$ and S2. The distribution of $V D R$ polymorphisms in the control group obeyed HWE $(P>0.05)$. There were no significant differences in the frequency of genotypes at selected VDR polymorphisms. The covariate-adjusted associations of $V D R$ SNPs with overweight/obesity and abdominal obesity are presented in Fig. 1 Under additive model and dominant models, none of the SNPs showed significant association with BMI or WC in the studied population. 
Table 1 Basic characteristics of the study participants

\begin{tabular}{|c|c|c|c|c|}
\hline \multirow[t]{2}{*}{ Parameter } & \multirow{2}{*}{$\begin{array}{l}\text { Normal } \\
253\end{array}$} & \multirow{2}{*}{$\begin{array}{l}\text { Overweight/obesity } \\
264\end{array}$} & \multirow[t]{2}{*}{$x^{2} / Z / t$} & \multirow[t]{2}{*}{$P$} \\
\hline & & & & \\
\hline Gender & & & 0.855 & 0.353 \\
\hline Male & $121(47.8 \%)$ & $137(51.9 \%)$ & & \\
\hline Female & $132(52.2 \%)$ & $127(48.1 \%)$ & & \\
\hline Age & & & 9.819 & 0.002 \\
\hline$\leq 45$ & $172(68.0 \%)$ & $144(54.5 \%)$ & & \\
\hline$>45$ & $81(32.0 \%)$ & $120(45.5 \%)$ & & \\
\hline $\mathrm{BMI}\left(\mathrm{kg} / \mathrm{m}^{2}\right)$ & $21.55(19.81,22.80)$ & $26.51(25.10,28.22)$ & -19.67 & $<0.001$ \\
\hline WC (cm) & $75.71 \pm 6.91$ & $90.20 \pm 8.12$ & -21.821 & $<0.001$ \\
\hline WHR & $0.83 \pm 0.06$ & $0.91 \pm 0.06$ & -14.53 & $<0.001$ \\
\hline $\mathrm{WHtR}$ & $0.47 \pm 0.05$ & $0.56 \pm 0.05$ & -22.52 & $<0.001$ \\
\hline Triceps skin fold thickness (mm) & $15.48 \pm 7.75$ & $21.57 \pm 8.29$ & -8.584 & $<0.001$ \\
\hline Body fat percentage (\%) & $19.05 \pm 6.45$ & $26.09 \pm 6.49$ & -12.174 & $<0.001$ \\
\hline $\mathrm{HDL}-\mathrm{C}(\mathrm{mmol} / \mathrm{L})$ & $1.42 \pm 0.29$ & $1.31 \pm 08.27$ & 3.656 & $<0.001$ \\
\hline LDL-C (mmol/L) & $2.16 \pm 0.73$ & $2.39 \pm 0.71$ & -3.500 & 0.001 \\
\hline $\mathrm{TC}(\mathrm{mmol} / \mathrm{L})$ & $4.04 \pm 0.95$ & $4.49 \pm 1.04$ & -5.170 & $<0.001$ \\
\hline $\mathrm{TG}(\mathrm{mmol} / \mathrm{L})$ & $0.78(0.58,1.19)$ & $1.33(0.84,2.14)$ & -8.127 & $<0.001$ \\
\hline
\end{tabular}

Data are given as the mean \pm SD, as $n$ (\%) or median (quartile range). BMI, body mass index; WC, waist circumference; WHR, waist-hip-ratio; WHtR, waist-heightratio; HDL-C, high-density lipoprotein cholesterol; LDL-C, low-density lipoprotein cholesterol; TC, total cholesterol; TG, triglyceride

\section{Linear regression-derived association of selected tagging VDR SNPs with BFP and triceps skinfold thickness in Han}

\section{Chinese}

The association of selected VDR SNPs with BFP and triceps skinfold thickness are presented in Table 2. Two SNPs (FokI and ApaI, rs2239179 and ApaI respectively) were significantly associated with BFP and triceps skinfold thickness. Assuming an additive genetic model on inheritance, for FokI $(\beta \pm S E=0.069 \pm 0.031, P=0.007)$, we observed that each additional rare allele resulted in a $6.9 \%$ increase in BFP, and for ApaI $(\beta \pm \mathrm{SE}=0.087 \pm$
$0.039, P=0.022)$, each additional rare allele resulted in a $8.7 \%$ increase in BFP; simultaneously, for rs2239179 $\beta \pm$ $\mathrm{SE}=0.074 \pm 0.028, P=0.001$ ), each additional rare allele resulted in $\mathrm{a} \sim 0.074-\mathrm{mm}$ increase in triceps skinfold thickness, and for ApaI $(\beta \pm \mathrm{SE}=0.122 \pm 0.034, P<$ 0.001 ), each additional rare allele resulted in a $0.122-\mathrm{mm}$ increase in triceps skinfold thickness.

Results are presented as $\beta \pm \mathrm{SE}, \beta$ coefficients represent the mean difference in body fat percentage and triceps skinfold thickness for each additional rare allele of the corresponding SNP. Linear regression analyses were

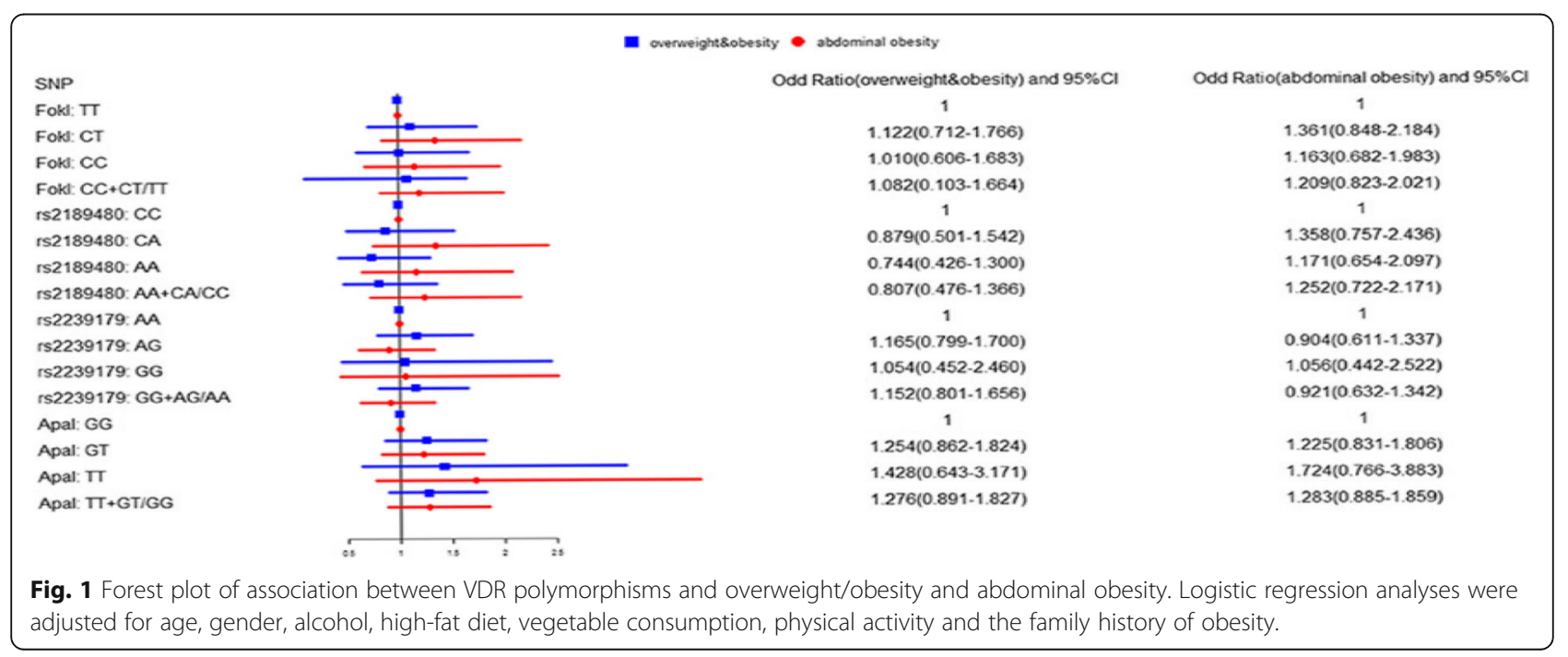


Table 2 Selected tagging VDR SNPs significantly associated with body fat percentage and triceps skin fold thickness

\begin{tabular}{|c|c|c|c|c|}
\hline \multicolumn{3}{|c|}{ Body fat percentage (\%) } & \multicolumn{2}{|c|}{ Triceps skinfold thickness (mm) } \\
\hline SNPS & $\beta \pm S E$ & $P$ & $\beta \pm S E$ & $P$ \\
\hline Fokl & $0.069 \pm 0.031$ & 0.007 & $0.051 \pm 0.030$ & 0.053 \\
\hline rs 2189480 & $0.041 \pm 0.029$ & 0.148 & $0.049 \pm 0.029$ & 0.065 \\
\hline rs2239179 & $-0.030 \pm 0.052$ & 0.560 & $0.074 \pm 0.028$ & 0.001 \\
\hline Apal & $0.087 \pm 0.039$ & 0.022 & $0.122 \pm 0.034$ & $<0.001$ \\
\hline
\end{tabular}

Results are presented as $\beta \pm S E, \beta$ coefficients represent the mean difference in body fat percentage and triceps skinfold thickness for each additional rare allele of the corresponding SNP. Linear regression analyses were adjusted for age, gender, alcohol, high-fat diet, vegetable consumption, physical activity and the family history of obesity

adjusted for age, gender, alcohol, high-fat diet, vegetable consumption, physical activity and the family history of obesity.

Higher BFP and triceps skinfold thickness susceptibility is due to the SNPs in VDR gene

Analysis of inter-gene (4SNPs) interaction obtained from GMDR was summarized in Table 3. The interaction model composed of FokI, rs2239179 and ApaI on the high BFP susceptibility was the best model $(P<0.001)$. Overall, the cross-validation consistency of this three-locus model was 10/10, and the testing accuracy was $57.5 \%$. Also, we found the best interaction combination involving these four SNPs on the risk of higher skinfold thickness. Overall, the cross-validation consistency of this four-locus model was 10/10, and the testing accuracy was $54.1 \%$. However, we did not find any significant interaction between the four SNPs and environmental factors (alcohol, high-fat dietary, exercise and family history of obesity) on these two phenotypes.

Table 3 GMDR models of gene-gene interactions on body fat percentage and triceps skin fold thickness

\begin{tabular}{|c|c|c|c|c|}
\hline Models & TBA1 & TBA2 & CVC & $P_{\text {sign }}$ \\
\hline \multicolumn{5}{|c|}{ Gene-gene interaction for body fat percentage ${ }^{a}$} \\
\hline Apal & 0.569 & 0.511 & $6 / 10$ & 0.172 \\
\hline Fokl, Apal & 0.602 & 0.524 & $6 / 10$ & 0.055 \\
\hline Fokl, Apal, rs2239179 & 0.632 & 0.575 & $10 / 10$ & 0.010 \\
\hline Fokl, Apal, rs2239179, rs2189480 & 0.657 & 0.553 & $10 / 10$ & 0.055 \\
\hline \multicolumn{5}{|c|}{ Gene-gene interaction for triceps skin fold thickness ${ }^{a}$} \\
\hline Apal & 0.593 & 0.595 & $10 / 10$ & 0.001 \\
\hline Fokl, Apal & 0.607 & 0.525 & $5 / 10$ & 0.055 \\
\hline Fokl, Apal, rs2189480 & 0.643 & 0.578 & $6 / 10$ & 0.001 \\
\hline Fokl, Apal rs2239179, rs2189480 & 0.655 & 0.541 & $10 / 10$ & 0.001 \\
\hline
\end{tabular}

\section{Adiposity-related metabolic parameters according to genotypes of VDR polymorphism}

The effects of the genotype distributions of the four SNPs on metabolic parameters were presented in Table 4. The results revealed that GT genotype of ApaI was associated with higher TC $(P=0.013)$ and LDL-C $(P=0.001)$.

\section{Discussion}

In the present study, we investigated the effect of the external environment and inherent variations of $V D R$ on obesity-related traits in humans. We found no significant link between $V D R$ SNPs and anthropometric measures (BMI and WC), but positive associations of $V D R$ SNPs with BFP and triceps skinfold thickness, FokI and ApaI for BFP, as well as rs2239179 and ApaI for triceps skinfold thickness. Furthermore, we identified significant gene-gene interactions with susceptibility to adiposity, three-locus model for BFP and four-locus model for triceps skinfold thickness. In addition, we found that $V D R$ variants were related to adiposity-related metabolic complications. Hence, our study provides evidence that polymorphisms in $V D R$ gene might play a role in regulating adipose tissue activity and susceptibility to adiposity among Han Chinese.

$V D R$ is expressed in various types of adipose tissues such as 3 T3-L1 adipocyte, human preadipocytes, differentiated adipocyte, human SAT and VAT [31-33]. Adipose tissue has multiple functions of lipids synthesizing, fatty acids transporting and adipokine secretions [15]. It is reported that vitamin $\mathrm{D}$ treatment blocked

Table 4 Association of VDR polymorphisms with metabolic parameters

\begin{tabular}{|c|c|c|c|c|}
\hline SNP & TG & $\mathrm{TC}$ & HDL-C & LDL-C \\
\hline Fokl & $P=0.924$ & $P=0.809$ & $P=0.611$ & $P=0.410$ \\
\hline$\pi$ & $1.385 \pm 1.091$ & $4.218 \pm 0.983$ & $1.348 \pm 1.091$ & $2.199 \pm 0.695$ \\
\hline $\mathrm{CT}$ & $1.400 \pm 1.310$ & $4.293 \pm 1.049$ & $1.357 \pm 0.283$ & $2.312 \pm 0.732$ \\
\hline $\mathrm{CC}$ & $1.445 \pm 1.379$ & $4.272 \pm 1.012$ & $1.382 \pm 0.295$ & $2.277 \pm 0.751$ \\
\hline rs2189480 & $P=0.778$ & $P=0.948$ & $P=0.992$ & $P=0.231$ \\
\hline $\mathrm{CC}$ & $1.034 \pm 1.075$ & $4.290 \pm 1.027$ & $1.364 \pm 0.296$ & $2.378 \pm 0.731$ \\
\hline CA & $1.425 \pm 1.411$ & $4.254 \pm 1.027$ & $1.360 \pm 0.297$ & $2.218 \pm 0.665$ \\
\hline$A A$ & $1.425 \pm 1.220$ & $4.282 \pm 1.024$ & $1.363 \pm 0.272$ & $2.306 \pm 0.782$ \\
\hline rs2239179 & $P=0.093$ & $P=0.205$ & $P=0.611$ & $P=0.877$ \\
\hline AA & $1.357 \pm 1.138$ & $4.241 \pm 1.019$ & $1.353 \pm 0.277$ & $2.279 \pm 0.734$ \\
\hline$A G$ & $1.552 \pm 1.551$ & $4.361 \pm 1.034$ & $1.377 \pm 0.292$ & $2.290 \pm 0.725$ \\
\hline GG & $1.015 \pm 0.608$ & $4.005 \pm 0.976$ & $1.399 \pm 0.353$ & $2.204 \pm 0.733$ \\
\hline Apal & $P=0.933$ & $P=0.013$ & $P=0.961$ & $P=0.001$ \\
\hline GG & $1.426 \pm 1.414$ & $4.195 \pm 0.998$ & $1.363 \pm 0.277$ & $2.199 \pm 0.670$ \\
\hline GT & $1.389 \pm 0.992$ & $4.437 \pm 1.076^{a}$ & $1.363 \pm 0.309$ & $2.432 \pm 0.822^{*}$ \\
\hline Tा & $1.358 \pm 1.550$ & $3.989 \pm 0.783$ & $1.347 \pm 0.220$ & $2.088 \pm 0.461$ \\
\hline
\end{tabular}

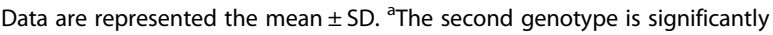
different from the first genotype 
adipogenesis in $V D R^{+/+}$cells but failed to do so in $\mathrm{VDR}^{-1-}$, indicating that $V D R$ might be required for adipogenesis [34]. Also, previous studies have shown that $V D R$ knockout mice shared lean phenotype and were resistance to diet-induced obesity, supporting the idea that $1 \alpha, 25(\mathrm{OH})_{2}-\mathrm{D}_{3} / V D R$ system modulates appetite and energy homeostasis [35, 36].

The association between $V D R$ genetic variants and anthropometric measures (BMI and WC) have been previously investigated mainly on British, Polish, American, Spanish and Saudi Arabian population. However, the results remained inconclusive [23, 24, 26, 37]. It is noted that a study involving 5224 participants in the 1958 British birth cohort did not find any link between $V D R$ SNPs and BMI and WC [23]. On the contrary, homozygous rare genotype was related to an increase in larger WC compared to common homozygous genotype in a sample of 1773 healthy American females [38]. In our study, there was no significant association between $V D R$ SNPs and BMI and WC in Han Chinese. Such differences may be attributed to different ethnic backgrounds [39]. Alternatively, different disease-causing alleles predominate in different study populations or variation exists in the degree of linkage disequilibrium between the markers and the disease alleles [40].

From the physiological point of view, it is not the degree of excess weight (as is measured by, for example BMI and WC), but the degree of body fatness acted as the risk factor. Evidence has been reported that skinfolds maybe more sensitive than BMI in detecting adiposity [41], as skinfolds are more directly associated than BMI with subcutaneous fat. Moreover, BFP had significantly stronger associations with obesity-related biomarkers than BMI did [42]. Previous study proved that VDR heterozygous mice showed significantly less fat accumulation than wild-type mice [43], so we hypothesized that $V D R$ SNPs may affect directly on body compositions (such as skinfold thickness and BFP) compared to indirect parameters (such as BMI and WC), which was verified by our results. We observed that the $\mathrm{T}$ allele of FokI and the $\mathrm{T}$ allele of ApaI were associated with an increase in BFP; the G allele of rs2239179 and the T allele of ApaI were associated with an increase in triceps skin fold thickness. Several lines of evidence should be considered while assessing the role of $V D R$ in adipogenesis. One possible explanation is that animal study suggest that $1,25(\mathrm{OH}) 2 \mathrm{D} 3 / V D R$ signaling exert suppressive effect on brown adipocyte differentiation, whereas brown adipose tissue is expressed in adult humans, functioning in non-shivering thermogenesis by uncoupling ATP synthesis from respiration, which plays an important role in energy expenditure [22]. Another underlying mechanism was that 1,25-dihydroxyvitamin $\mathrm{D}$ stimulates adipose leptin production in a VDR-dependent manner, and protected transgenic mice from body adipose accumulation [44].

ApaI, rs2189480 and rs2239179 are located in the 3' untranslated region (UTR) or intron region and are unlikely to cause a disease. The FokI variants, located in the codon initiating translation that results in a smaller protein with increased capacity of 1,25-dihydroxyvitamin $\mathrm{D}$ binding [45], and accelerating adipogenesis in primary mouse and human preadipocytes, which was evidenced by increased expressions of adipogenic markers and lipid accumulation [46]. Therefore, analyses on VDR SNPs and their interrelations are being demanded as they may affect expression and activity of VDR. Our results suggested that the interactions between these four SNPs variants may lead to adiposity through linkage disequilibrium (LD), which may extend into 3'regulatory region (containing of the UTR); whereas polymorphisms in the 3'UTR region regulate gene expression by modulating messenger RNA stability and hence likely to affect the intracellular level of $V D R$ [47]. Meanwhile the vitamin D signaling and adipogenesis are affected by $V D R$ expression in a concentration-depending manner [21]. The relationship has established between SNPs in $V D R$ gene and the body compositions so far, and the mechanism of which needs to be verified in future studies.

Emerging evidence indicates that variations in the $V D R$ polymorphisms may contribute to dyslipidemia. In the present study, the ApaI homozygous rare genotype displayed a significant association with increased levels of TC and LDL-C. Also supported by Jia et al's conclusion as VDR SNPs are significantly correlated with risk of dyslipidemia and serum LDL levels in Chinese Han population [48]. In obese people, enhanced secretion of triglyceride-rich lipoprotein and impaired clearance of these lipoproteins increase the accumulation of visceral adiposity [49]. Furthermore, VDR mutational alleles carriers are commonly related to lower levels of serum $25(\mathrm{OH}) \mathrm{D}$, higher lipid parameters and abnormal inflammatory biomarker in obese individuals [50]. The action of vitamin $\mathrm{D}$ is mediated through vitamin $\mathrm{D}$ receptor, a nuclear transcription-regulating factor that regulates de novo lipid synthesis, thereby contributing to the development of obesity [51]. Hence, VDR gene may influence the progression of adiposity activity via dyslipidemia.

There are several limitations to the present study including a lack of other genes that contribute to synthesis, transportation and degradation form of vitamin $\mathrm{D}$ such as CYP2R1, GC, CYP27B1 and CYP24A1. Another potential limitation is that associations with intermediate parameters such as adipokine secretion including leptin and adiponectin could have strengthened our findings; however, we did not have such data. Nevertheless, our study do have some strengths. First of all, our participants were all Han Chinese, eliminating population 
admixture as a potential drawback. Then, we excluded participants who had taken vitamin D/calcium supplements, avoiding external environmental interference. Last of all, one of the main strengths of our study was that we measured skinfold thickness and BFP which directly reflect adiposity accumulation. Thus we were able to study the association between $V D R$ polymorphisms and the most active form of adiposity, which is not focused on by previous studies. The findings of this study may provide a new insight for association of $V D R$ polymorphism and adiposity.

\section{Conclusions}

In summary, our study suggests that $V D R$ variants are associated with susceptibility to adiposity in Han Chinese. The genetic factors that contribute to adiposity are certainly more complex than to be explained entirely by variations in a single gene. We acknowledge that the results are limited by ethnic specificity and relatively small sample size, so these results need to be replicated and confirmed in a large-scale study and more potential functional $V D R$ polymorphisms should be detected.

\section{Additional file}

Additional file 1: Table S1. Allele and genotype frequencies of VDR polymorphism and risk of overweight and obesity. Table S2. Allele and genotype frequencies of VDR polymorphism and risk of abdominal obesity (DOCX 20 kb)

\section{Abbreviations}

BFP: Body fat percentage; BM: Body mass index; CVC: Cross-validation consistency; GMDR: General multifactor dimensionality reduction; HDLC: High-density lipoprotein cholesterol; HWE: Hardy-Weinberg equilibrium; LD: Linkage disequilibrium; LDL-C: Low-density lipoprotein cholesterol; NCDs: Non-communicable diseases; SAT: Subcutaneous adipose tissue; SNPs: Single nucleotide polymorphisms; TBA1: Training balanced accuracy; TBA2: Testing balanced accuracy; TC: Total cholesterol; TG: Triglyceride; UTR: Untranslated region; VAT: Visceral adipose tissue; VDR: Vitamin D receptor; WC: Waist circumference; WHR: Waist-hip-ratio; WHtR: Waist-heightratio

\section{Acknowledgements}

We thank all the participants and research staff in the study.

\section{Funding}

This work was supported by the National Nature Science Foundation of China (grants number 81872626, 81573151, and 81,573,243), Science and Technology Foundation for Innovation Talent of Henan Province (No. 154200510010).

\section{Availability of data and materials}

The datasets used and/or analyzed during the current study are available from the corresponding author on reasonable request.

\section{Authors' contributions}

$\mathrm{XL}$ and FS drafted and revised the paper, JW and $\mathrm{HH}$ contributed in DNA extraction and genotyping, YW, DZ and HS cleaned and analyzed the data, FS, SY and FY involved in the collection of data, WL, CW and YB reviewed and interpreted the results. All authors read and approved the final manuscript.

\section{Ethics approval and consent to participate}

Informed consent was obtained from all individual participants included in the study, and the study was approved by the Ethics Committees of

Zhengzhou University.

\section{Consent for publication}

All the authors provided written informed consent for the publication of the results of this study.

\section{Competing interests}

The authors declare that they have no competing interests.

\section{Publisher's Note}

Springer Nature remains neutral with regard to jurisdictional claims in published maps and institutional affiliations.

\section{Author details}

${ }^{1}$ Department of Nutrition and Food Hygiene, College of Public Health, Zhengzhou University, 100 Kexue Avenue, Henan 450001, China.

${ }^{2}$ Department of Occupational and Environmental Health Science, College of Public Health, Zhengzhou University, 100 Kexue Avenue, Henan 450001, China. ${ }^{3}$ Department of Epidemiological and Biostatistics, College of Public Health, Zhengzhou University, 100 Kexue Avenue, Henan 450001, China.

Received: 21 January 2019 Accepted: 21 March 2019

Published online: 11 April 2019

\section{References}

1. Obesity and overweight. Word Health Organization. [http://www.who.int/ en/news-room/fact-sheets/detail/obesity-and-overweight Accessed 16 Feb 2018].

2. Xi B, Liang $Y, H e T$, Reilly $K H, H u Y$, Wang $Q$, et al. Secular trends in the prevalence of general and abdominal obesity among Chinese adults, 1993 2009. Obes Rev. 2012;13:287-96. https://doi.org/10.1111/j.1467-789X.2011. 00944.x

3. The L. Obesity: a growing threat to health in China. Lancet. 2014;384:716. https://doi.org/10.1016/S0140-6736(14)61421-5.

4. Plourde B, Sarrazin JF, Nault I, Poirier P. Sudden cardiac death and obesity. Expert Rev Cardiovasc Ther. 2014;12:1099-110. https://doi.org/10.1586/ 14779072.2014.952283.

5. Bedogni $G$, lughetti L, Ferrari M, Malavolti M, Poli M, Bernasconi S, et al. Sensitivity and specificity of body mass index and skinfold thicknesses in detecting excess adiposity in children aged 8-12 years. Ann Hum Biol. 2003; 30:132-9.

6. Kelly AS, Dengel DR, Hodges J, Zhang L, Moran A, Chow L, et al. The relative contributions of the abdominal visceral and subcutaneous fat depots to cardiometabolic risk in youth. Clinical obesity. 2014;4:101-7. https://doi.org/10.1111/cob.12044.

7. Freedman DS, Dietz WH, Srinivasan SR, Berenson GS. Risk factors and adult body mass index among overweight children: the Bogalusa heart study. Pediatrics. 2009;123:750. https://doi.org/10.1542/peds.2008-1284.

8. Ali O, Cerjak D, Kent JW, James R, Blangero J, Zhang Y. Obesity, central adiposity and cardiometabolic risk factors in children and adolescents: a family-based study. Pediatric obesity. 2014;9:e58-62. https://doi.org/10.1111/ j.2047-6310.2014.218.x.

9. Lim S, Meigs JB. Ectopic fat and cardiometabolic and vascular risk. Int J Cardiol. 2013;169:166-76. https://doi.org/10.1016/j.jijcard.2013.08.077.

10. Hu Y, Chen J, Wang R, Li M, Yun C, Li W, et al. Vitamin D nutritional status and its related factors for Chinese children and adolescents in 2010-2012. Nutrients. 2017:9:1024. https://doi.org/10.3390/nu9091024.

11. Chen J, Yun C, He Y, Piao J, Yang L, Yang X. Vitamin D status among the elderly Chinese population: a cross-sectional analysis of the 2010-2013 China national nutrition and health survey (CNNHS). Nutr J. 2017;16:3. https://doi.org/10.1186/s12937-016-0224-3.

12. Caron-Jobin M, Morisset AS, Tremblay A, Huot C, Legare D, Tchernof A. Elevated serum $25(\mathrm{OH}) \mathrm{D}$ concentrations, vitamin $\mathrm{D}$, and calcium intakes are associated with reduced adipocyte size in women. Obesity (Silver Spring). 2011;19:1335-41. https://doi.org/10.1038/oby.2011.90.

13. González L, Ramos-Trautmann G, Díaz-Luquis GM, Pérez CM, Palacios C. Vitamin D status is inversely associated with obesity in a clinic-based 
sample in Puerto Rico. Nutr Res (New York, NY). 2015;35:287-93. https://doi. org/10.1016/j.nutres.2015.02.001.

14. Greene-Finestone LS, Garriguet D, Brooks S, Langlois K, Whiting SJ. Overweight and obesity are associated with lower vitamin D status in Canadian children and adolescents. Paediatr Child Health. 2017;22:438-44. https://doi.org/10.1093/pch/pxx116.

15. Wood RJ. Vitamin D and adipogenesis: new molecular insights. Nutr Rev. 2008;66:40-6. https://doi.org/10.1111/j.1753-4887.2007.00004.x.

16. Abbas MA. Physiological functions of vitamin D in adipose tissue. J Steroid Biochem Mol Biol. 2017;165:369-81. https://doi.org/10.1016/j.jsbmb.2016.08. 004.

17. Vinh qu c Luong K, Nguyễn LTH. The beneficial role of vitamin $D$ in obesity: possible genetic and cell signaling mechanisms. Nutr J. 2013;12:89 https://doi.org/10.1186/1475-2891-12-89.

18. Rosenstreich SJ, Rich C, Volwiler W. Deposition in and release of vitamin D3 from body fat: evidence for a storage site in the rat. J Clin Invest. 1971;50: 679-87. https://doi.org/10.1172/JCl106538.

19. Ching S, Kashinkunti S, Niehaus MD, Zinser GM. Mammary adipocytes bioactivate 25-hydroxyvitamin $\mathrm{D}(3)$ and signal via vitamin $\mathrm{D}(3)$ receptor, modulating mammary epithelial cell growth. J Cell Biochem. 2011;112:3393405. https://doi.org/10.1002/jcb.23273.

20. Ryynanen J, Neme A, Tuomainen TP, Virtanen JK, Voutilainen S, Nurmi T, et al. Changes in vitamin $D$ target gene expression in adipose tissue monitor the vitamin D response of human individuals. Mol Nutr Food Res. 2014;58: 2036-45. https://doi.org/10.1002/mnfr.201400291.

21. Blumberg JM, Tzameli I, Astapova I, Lam FS, Flier JS, Hollenberg AN. Complex role of the vitamin $\mathrm{D}$ receptor and its ligand in Adipogenesis in 3T3-L1 cells. J Biol Chem. 2006;281:11205-13. https://doi.org/10.1074/jbc. M510343200.

22. Ricciardi CJ, Bae J, Esposito D, Komarnytsky S, Hu P, Chen J, et al. 1,25Dihydroxyvitamin D3/vitamin D receptor suppresses brown adipocyte differentiation and mitochondrial respiration. Eur J Nutr. 2015:54:1001-12. https://doi.org/10.1007/s00394-014-0778-9.

23. Vimaleswaran KS, Cavadino A, Berry DJ, Genetic Investigation of Anthropometric Traits C, Whittaker JC, Power C, et al. Genetic association analysis of vitamin D pathway with obesity traits. Int J Obes. 2013;37:1399406. https://doi.org/10.1038/ijo.2013.6.

24. Filus A, Trzmiel A, Kuliczkowska-Plaksej J, Tworowska U, Jedrzejuk D, Milewicz A, et al. Relationship between vitamin D receptor Bsml and Fokl polymorphisms and anthropometric and biochemical parameters describing metabolic syndrome. Aging Male. 2008;11:134-9. https://doi.org/10.1080/ 13685530802273426 .

25. Al-Hazmi AS, Al-Mehmadi MM, Al-Bogami SM, Shami AA, Al-Askary AA Alomery AM, et al. Vitamin D receptor gene polymorphisms as a risk factor for obesity in Saudi men. Electron Physician. 2017;9:5427-33. https://doi.org/ $10.19082 / 5427$.

26. Hajj A, Chedid R, Chouery E, Megarbané A, Gannagé-Yared M-H. Relationship between vitamin $D$ receptor gene polymorphisms, cardiovascular risk factors and adiponectin in a healthy young population. Pharmacogenomics. 2016;17: 1675-86. https://doi.org/10.2217/pgs-2016-0045.

27. Al-Daghri NM, Al-Attas OS, Alkharfy KM, Khan N, Mohammed AK, Vinodson $B$, et al. Association of VDR-gene variants with factors related to the metabolic syndrome, type 2 diabetes and vitamin D deficiency. Gene. 2014; 542:129-33. https://doi.org/10.1016/j.gene.2014.03.044.

28. Chen C, Lu FC. The guidelines for prevention and control of overweight and obesity in Chinese adults. Biomed Environ Sci. 2004;17(Suppl):1. https:// doi.org/10.1111/j.1365-2028.2008.00991.x.

29. Alberti KGMM, Zimmet $P$, Shaw J. The metabolic syndrome-a new worldwide definition. Lancet. 2005;366:1059-62. https://doi.org/10.1016/ S0140-6736(05)67402-8.

30. Lou X-Y, Chen G-B, Yan L, Ma JZ, Zhu J, Elston RC, et al. A generalized combinatorial approach for detecting gene-by-gene and gene-byenvironment interactions with application to nicotine dependence. Am J Hum Genet. 2007;80:1125-37. https://doi.org/10.1086/518312.

31. Kamei Y, Kawada T, Kazuki R, Ono T, Kato S, Sugimoto E. Vitamin D receptor gene expression is up-regulated by 1, 25-Dihydroxyvitamin D3 in 3T3-L1 Preadipocytes. Biochem Biophys Res Commun. 1993;193:948-55. https://doi. org/10.1006/bbrc.1993.1717.

32. Ding C, Gao D, Wilding J, Trayhurn P, Bing C. Vitamin D signalling in adipose tissue. Br J Nutr. 2012;108:1915-23. https://doi.org/10.1017/ S0007114512003285.
33. Stephen C, Soumya K, Niehaus MD, Zinser GM. Mammary adipocytes bioactivate 25-hydroxyvitamin D? And signal via vitamin D? Receptor, modulating mammary epithelial cell growth. J Cell Biochem. 2011;112:3393405. https://doi.org/10.1002/jcb.23273.

34. Kong J, Li YC. Molecular mechanism of 1,25-dihydroxyvitamin D3 inhibition of adipogenesis in 3T3-L1 cells. Am J Phys Endocrinol Metab. 2006;290: E916-24. https://doi.org/10.1152/ajpendo.00410.2005.

35. Narvaez CJ, Matthews D, Broun E, Chan M, Welsh J. Lean phenotype and resistance to diet-induced obesity in vitamin $\mathrm{D}$ receptor knockout mice correlates with induction of uncoupling protein-1 in white adipose tissue. Endocrinology. 2009;150:651-61. https://doi.org/10.1210/en.2008-1118.

36. Wong KE, Szeto FL, Zhang W, Ye H, Kong J, Zhang Z, et al. Involvement of the vitamin $\mathrm{D}$ receptor in energy metabolism: regulation of uncoupling proteins. Am J Phys Endocrinol Metab. 2009;296:E820-8. https://doi.org/10. 1152/ajpendo.90763.2008.

37. Correa-Rodríguez M, Carrillo-Ávila JA, Schmidt-RioValle J, González-Jiménez E, Vargas S, Martín J, et al. Genetic association analysis of vitamin D receptor gene polymorphisms and obesity-related phenotypes. Gene. 2018;640:51-6. https://doi.org/10.1016/j.gene.2017.10.029.

38. Ochs-Balcom HM, Chennamaneni $R$, Millen AE, Shields PG, Marian $C$, Trevisan $M$, et al. Vitamin $D$ receptor gene polymorphisms are associated with adiposity phenotypes. Am J Clin Nutr. 2011;93:5-10. https://doi.org/10. 3945/ajcn.2010.29986.

39. Jin T, Aikemu A, Zhang M, Geng T, Feng T, Kang L, et al. Genetic polymorphisms analysis of Pharmacogenomic VIP variants in Miao ethnic Group of Southwest China. Med Sci Monit. 2015;21:3769-76. https://doi.org/ 10.12659/MSM.895191

40. Colhoun HM, McKeigue PM, Smith GD. Problems of reporting genetic associations with complex outcomes. Lancet. 2003;361:865-72. https://doi. org/10.1016/S0140-6736(03)12715-8.

41. Sarría A, Moreno L, Garcí-Llop L, Fleta J, Morellón M, Bueno M. Body mass index, triceps skinfold and waist circumference in screening for adiposity in male children and adolescents. Acta Paediatr. 2001;90:387-92. https:/doi. org/10.1111/j.1651-2227.2001.tb00437.x.

42. Lee DH, Keum N, Hu FB, Orav EJ, Rimm EB, Sun Q, et al. Development and validation of anthropometric prediction equations for lean body mass, fat mass and percent fat in adults using the National Health and nutrition examination survey (NHANES) 1999-2006. Br J Nutr. 2017;118:858-66. https://doi.org/10.1017/S0007114517002665.

43. de Paula FJ, Dick-de-Paula I, Bornstein S, Rostama B, Le P, Lotinun S, et al. VDR haploinsufficiency impacts body composition and skeletal acquisition in a gender-specific manner. Calcif Tissue Int. 2011;89:179-91. https://doi. org/10.1007/s00223-011-9505-1.

44. Juan K, Yunzi C, Guojun Z, Qun Z, Yan Chun L. 1,25-Dihydroxyvitamin D3 upregulates leptin expression in mouse adipose tissue. J Endocrinol. 2013; 216:265-71. https://doi.org/10.1530/JOE-12-0344.

45. Miyamoto HAK. A vitamin D receptor gene polymorphism in the translation initiation codon: effect on protein activity and relation to bone mineral density in Japanese women. JMBR. 2009;12:915-21. https//doi.org/10.1359/jbmr.1997.12.6.915.

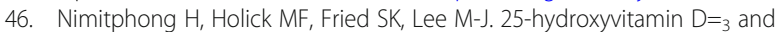
1,25-dihydroxyvitamin $D_{3}$ promote the differentiation of human subcutaneous preadipocytes. PLoS One. 2012;7:e52171. https://doi.org/10. 1371/journal.pone.0052171.

47. Fang $\mathrm{Y}$, van Meurs JBJ, d'Alesio A, Jhamai M, Zhao H, Rivadeneira F, et al. Promoter and $3^{\prime}$-untranslated-region haplotypes in the vitamin d receptor gene predispose to osteoporotic fracture: the Rotterdam study. Am J Hum Genet. 2005;77:807-23. https://doi.org/10.1086/497438.

48. Jia J, Tang Y, Shen C, Zhang N, Ding H, Zhan Y. Vitamin D receptor polymorphism rs2228570 is significantly associated with risk of dyslipidemia and serum LDL levels in Chinese Han population. Lipids Health Dis. 2018;17: 193. https://doi.org/10.1186/s12944-018-0819-0.

49. Björnson E, Adiels M, Taskinen MR, Borén J. Kinetics of plasma triglycerides in abdominal obesity. Curr Opin Lipidol. 2016;28:11. https://doi.org/10.1097/ MOL.0000000000000375.

50. Zaki M, Kamal S, Basha WA, Youness E, Ezzat W, El-Bassyouni H, et al. Association of vitamin $D$ receptor gene polymorphism (VDR) with vitamin $D$ deficiency, metabolic and inflammatory markers in Egyptian obese women. Genes Dis. 2017:4:176-82. https://doi.org/10.1016/.gendis.2017.07.002.

51. Slusher AL, MCAllister MJ, Huang C-J. A therapeutic role for vitamin D on obesity-associated inflammation and weight-loss intervention. Inflamm Res. 2015;64:565-75. https://doi.org/10.1007/s00011-015-0847-4. 